\title{
Access to infertility investigations and treatment in couples infected with HIV: questionnaire survey
}

\author{
Ade Apoola, Judith tenHof, P S Allan
}

Life expectancy among patients infected with HIV has increased since combination anti-HIV therapies were introduced. This has led to calls for infertility in people with HIV to be treated in an identical way to that in patients with other chronic medical conditions. ${ }^{1}$

Two broad groups of patients infected with HIV are likely to request infertility treatment. The first group consists of couples in which only one partner is infected with HIV (serodiscordant couples) who would like to have children but who wish to avoid the transmission of the virus to the uninfected partner; they may not be subfertile. The second group consists of serodiscordant couples who are subfertile and have tried to conceive spontaneously (with the attendant risks) without success and subfertile couples in which both partners are infected with HIV who would like to have children. We determined whether couples presenting to infertility clinics are offered investigations and treatment when one or both partners are known to be infected with HIV.

\section{Methods and results}

Clinics providing assisted conception as of December 2000 were identified from the records of the Human Fertilisation and Embryology Authority, which licenses the use of such techniques in Britain (www.hfea.gov.uk). All 75 clinics were sent a questionnaire (see appendix on BMJ's website). Statistical relations between the categorial variables were analysed with SPSS software, using $\chi^{2}$ analysis or the Cochran $Q$ test for related dichotomous variables.

We received responses from $57(76 \%)$ of the 75 clinics. Forty one units (72\%) had a policy on treating patients infected with HIV. Most (25 (61\%)) of these had not seen a patient infected with HIV in the previous year. Only one $(6 \%)$ of 17 units that had seen a patient infected with HIV in the previous year did not have a policy. The responses to some of the questions asked are given in the table.

Units that had seen patients infected with HIV in the past year were more likely than units that had not to investigate or to offer treatment when the man was infected with HIV (13 (87\%) v $20 \quad(57 \%)$ for investigation, $\mathrm{P}=0.05 ; 12(75 \%)$ v $13(37 \%)$ for treatment, $\mathrm{P}=0.01)$. The same trend was not seen when the woman or both partners were infected with HIV.

We further analysed the responses by looking at differences between clinics in and outside London; these results are available on the $B M J$ 's website.

\section{Comment}

In general, infertility clinics are biased against patients infected with HIV-for example, only $44 \%$ of units would treat a couple where only the man was infected with HIV. With this type of serodiscordant couple,

donor insemination is a safe technique, and couples wishing to have a child that is theirs biologically would benefit from sperm washing. ${ }^{2}$

The risk of the virus being transmitted to the child in couples in which both partners are infected with HIV can be reduced by the mother taking antiretroviral drugs during pregnancy and labour ${ }^{4}$ and having a caesarean section, by the child receiving antiretroviral therapy at birth, and by avoiding breast feeding.

The Human Fertilisation and Embryology Act 1990 requires the welfare of the child to be taken into account before treatment starts, but it does not exclude any category of woman from being considered for infertility treatment. A blanket refusal to provide infertility investigations and treatment to couples infected with HIV may lead to an increase in seroconversion of the uninfected partners of serodiscordant couples trying to conceive naturally. ${ }^{5}$

Not all patients infected with HIV will be suitable for infertility treatment, but whether couples are offered assisted conception in Britain is a lottery, as there are no established guidelines. Centres offering assisted conception should have a less restrictive attitude towards patients infected with HIV.

We thank Lesley Morris for her secretarial support.

Contributors: AA designed the study, collected and analysed the data, and drafted the paper. JtH conceived the idea for the project and contributed to the design of the questionnaire. PSA contributed to the design of the questionnaire and to revising the paper. All authors commented on drafts of the paper. AA is the guarantor.

Funding: None.

Competing interests: None declared.

1 Minkoff H, Santoro N. Ethical considerations in the treatment of infertility in women with human immunodeficiency virus infection. $N$ Engl J Med 2000;342:1748-50.

2 Semprini AE. Insemination of HIV-negative women with processed semen of HIV-positive partners. Lancet 1993;341:1343-4.

3 Gilling-Smith C, Smith JR, Semprini AE. HIV and infertility: time to treat. BMJ 2001;322:566-7.

4 Connor EM, Sperling RS, Gelber R, Kiselev P, Scott G, O'Sullivan MJ, et al for the Pediatric AIDS Clinical Trials Group Protocol 076 Study Group. Reduction of maternal-infant transmission of human immunodeficiency virus type 1 with zidovudine treatment. $N$ Engl J Med 1994;331:1173-80.

5 Mandelbrot L, Heard I, Henrion-Geant E, Henrion R. Natural conception in HIV-negative women with HIV-infected partners. Lancet 1997;349:850-1.

(Accepted 25 June 2001)

Department of Genitourinary Medicine, Coventry and Warwickshire Hospital, Coventry CV1 4FH

Ade Apoola specialist registrar

P S Allan consultant

Universitair

Medisch Centrum, Heidelberglaan 100 , 3584 Utrecht,

Netherlands

Judith tenHof registrar

Correspondence to: A Apoola

apoola@yahoo.com

BMJ 2001;323:1285

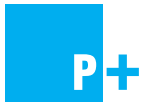

The questionnaire used in this study and further results appear on the BMJ's website

Responses from infertility clinics asked whether they would offer infertility investigations and treatment to couples when one or both partners were infected with HIV. Values are numbers (percentages)

\begin{tabular}{|c|c|c|c|}
\hline & Yes & No & No response \\
\hline \multicolumn{4}{|c|}{ Would you offer infertility investigations to a couple when: } \\
\hline The male partner is HIV positive? & $33(58)^{*}$ & $17(30)$ & $7(12)$ \\
\hline The female partner is HIV positive? & $25(44)$ & $24(42)$ & $8(14)$ \\
\hline Both partners are HIV positive? & $24(42)$ & $25(44)$ & $8(14)$ \\
\hline \multicolumn{4}{|c|}{ Would you offer infertility treatment to a couple when: } \\
\hline The male partner is HIV positive? & $25(44)^{*}$ & $26(46)$ & $6(10)$ \\
\hline The female partner is HIV positive? & $14(25)$ & $36(63)$ & $7(12)$ \\
\hline Both partners are HIV positive? & $12(21)$ & $38(67)$ & $7(12)$ \\
\hline
\end{tabular}

